\title{
Associations Between Physical Activity and Gross Motor Skills with Social Development in Children with Learning Disabilities
}

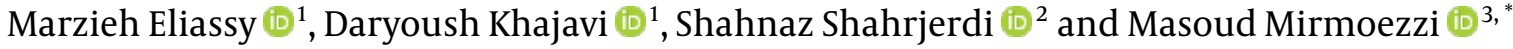 \\ ${ }^{1}$ Department of Physical Education and Sport Sciences, Faculty of Humanities, University of Arak, Arak, Iran \\ ${ }^{2}$ Department of Physiology and Sports Pathology, Faculty of Sport Sciences, Arak University, Arak, Iran \\ ${ }^{3}$ Department of Physical Education and Sports Sciences, Islamic Azad University, Central Tehran Branch, Tehran, Iran \\ "Corresponding author: Department of Physical Education and Sports Sciences, Islamic Azad University, Central Tehran Branch, Tehran, Iran. Email: \\ massoudmirmoezi@live.com \\ Received 2021 November 03; Revised 2021 December 13; Accepted 2021 December 24.
}

\begin{abstract}
Background: Social development is a fundamental aspect of motor development in children. It has been shown that children with learning disorders have different gross motor skills and physical activity compared to typically developing peers.

Objectives: Since developmental domains interact with each other and children with learning disabilities often have difficulties that go far beyond those in school homework, the purpose of this study is to investigate the relationship between physical activity and gross motor skills with social development for children with learning disabilities.

Methods: In children with learning disorder ( $n=82 ; 49$ boys, 33 girls), gross motor skills and physical activity were assessed respectively with the Test of Gross Motor Development-2 and Past Year Physical Activity Questionnaire. Vineland Social Maturity Scale was used to evaluate the social development of participants. The Pearson correlation coefficient is used to association between variables. The significance for test was set at $\mathrm{P}<0.05$.

Results: Locomotor and object-control were significantly associated with social development $(r=0.60, P<0.001)$ and $(r=0.44, P$ $=0.003)$, respectively. Organized activities were significantly associated with social development $(r=0.69, P=0.001)$. Also, gross motor skills and organized activities were able to predict the social development of children with learning disorder $(\mathrm{R} 2=0.29, \mathrm{~F}=$ 15.78).

Conclusions: Children with higher levels of organized activities and motor skills had higher social development. As a result, gross motor skills and organized physical activity are especially important for children with learning disabilities.
\end{abstract}

Keywords: Locomotion, Exercise, Learning Disabilities, Child

\section{Background}

Learning disabilities cover a wide range of abnormalities and problems, these defects may occur in children's verbal and expressive ability, or in the form of loss of mathematical intelligence or even in the form of difficulty in reading and writing. A learning disorder (LD) specific learning disability refer to an information processing problem that prevents a person from learning a skill and a neurological condition that affects the brain's ability to send, receive, and process information. These processing problems can interfere with the classroom and student activities. After experiencing failure, the child gradually loses self-confidence and expresses disgust with any general activity. It seems that increasing physical activity (PA) may lead to a higher level of gross motor skills (GMS). GMS are those which require whole body movement and which involve the large muscles of the body to perform everyday functions, such as standing, jumping and running (1). Investigating and solving the problems of these students is one of the necessities of the education system, which helps to discover and control the factors that lead to educational and learning problems in schools.

Studying the social development of children with LD is important and can be attributed to such things as deficits in cognitive processing and more severe disorder in adolescence and early adulthood $(2,3)$. Social learning is one of the most effective environmental factors in motor development. Socialization requires many behaviors, such as social skills, physical and motor skills, mood, worthiness, knowledge, attitudes, normal behavior, temperament, and discipline. Socialization is very important area in motor development because motor experiences and competence are affected by the emotional-social domain (4). Various studies have reported that problems that students with 
LD may encounter in education include issues related to lack of proper communication and interaction with peer groups and as a result of social isolation, low self-efficacy and self-esteem and inappropriate social behaviors that can reduce organized physical activity and increase static and sedentary activities $(2,4,5)$.

The growth and development of human personality has cognitive, motor perceptual and social development aspects.

The growth and development of human personality has cognitive, motor perceptual and social development aspects. Socialization occurs through social interaction that is associated with sports participation, and social development can be related to physical activity and growth (5). One way to increase physical activity may be to develop a high level of GMS. Literature review focuses on the positive relationship between GMS and PA in children. However, there is no adequate information on the relationship between competence in GMS and PA on social development, especially in children with LD who have difficulty acquiring motor and cognitive skills $(1,4)$.

Given that 3 to 10 percent of children have LD and the problems of these children are getting bigger every day due to the complexity of living conditions, so addressing the problems of these children to improve their conditions is essential (4). The results of numerous studies on the development of these children are evidence of their weakness in GMS and their social development $(1,5)$.

\section{Objectives}

Since physical activity may affect gross motor skills competence, and a few research studies have been found to examine the relationship between these factors and socioemotional development in children with LD; the present study aims to determine the relationship associations between gross motor development and physical activity with social development for children with learning disabilities.

\section{Methods}

\subsection{Participants}

The statistical population was students with LD in primary school in Ilam and 82 children with LD ( 49 boys and 33 girls), aged between 7 and 11 years old (mean age: 9.49 \pm 1.4 years) participated in study. Children with LD were selected based on the diagnosis and judgment of psychiatrist and psychologist approved by the Iran Ministry of Education, based on the statistical and diagnostic guide to mental disorders (American Psychiatric Association, 2013). The sample size was estimated based on G-Power software with a power of $80 \%$ and alpha 0.05 . Thirty one children were excluded from the study because of inclusion and exclusion criteria (Figure 1). Prior to data collection, written informed consent was obtained from the participant's parents or carers.

\subsection{Inclusion and Exclusion Criteria}

Inclusion criteria were employment in one of the primary schools in Ilam at the time of research, having a minimum of 6 years and a maximum of 11 years and 11 months, having physical health and difficulty in one or more areas of learning. The exclusion criteria included, evidence of gross neurological deficits and severe emotional disturbances and comorbid disorder, i.e. having ADHD and Autism disorders.

\subsection{Tools}

Test of gross motor development (TGMD-2) is one of the most widely used assessment tools to assess GMS of children. TGMD-2 is performed through a qualitative assessment of 12 GMS, including locomotor skills (run, gallop, hop, leap, jump, and slide) and object-control skills (two-hand strike, stationary bounce, catch, kick, overhand throw, and underhand roll). In this test each motor skills includes several behavioral components that are expressed as criteria for performance. In general, these behaviors express a mature pattern of skill. If the child performs the behavioral component correctly, he/she gets a score of 1 ; otherwise, he/she gets a score of 0 . After completing this process, two attempts are made for each item; the examiner collects the scores of the two attempts to obtain the raw skill score of each item. Skills score is added to get the raw score (highest value is 48) of subscales (locomotor and object-control skills) (6). In Ulrich's study, good validity and reliability for children with LD are expressed (7).

To evaluate daily activities, the Past Year Physical Activity Questionnaire (PY-PAQ) was used which consists of two parts: organized activities and static activities (8). Organized activities in the present study are activities that have been performed under the supervision of an instructor, teacher or mentor at specific times, and static activities are those that are performed statically and without displacement (8). Some of the mentioned organized activities mostly require the use of displacement skills (such as swimming, gymnastics) and others more, deal with object manipulated skills (such as football, basketball). This questionnaire has acceptable validity and reliability (9).

The Vineland Social Maturity Scale (VSMS) is one of the evolutionary scales that deals with the degree to which an individual is able to meet his/her practical needs and 


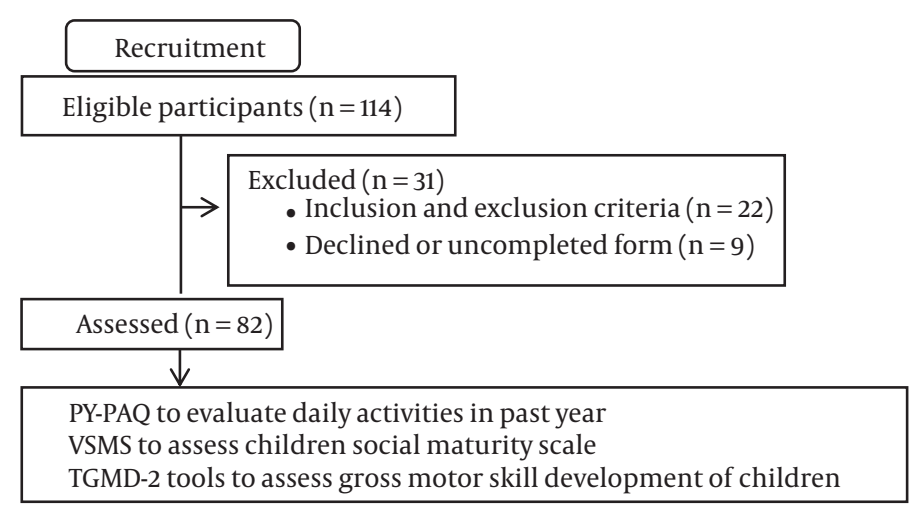

Analyses

Figure 1. Flowchart of the recruitment process.

take responsibility. This questionnaire is intended from birth to 16 years. This test is more effective in younger children, especially the mentally retarded. The VSMS measures eight scales: locomotion, occupation, communication, socialization, self-direction, self-help eating, self-help dressing and self-help general. This scale obtains a proximate IQ using social age and social quotient (10). This questionnaire has acceptable validity and reliability in Iran (11).

\subsection{Data Collection}

First, PY-PAQ and VSMS questionnaires were distributed among students' parents and the necessary explanations were provided on how to fill in the questionnaires. PY-PAQ was completed by the parents and then the average minutes of these activities in the organized activities section were calculated based on Formula 1: Sum of (Months per year $\times$ weeks per month $\times 4.348$ minutes per day /52.177 weeks). The second part is related to the static activities that the child does on a daily basis (such as watching TV, doing homework). The scores obtained from this section are given in Formula 2 and the amount of static activities per week was calculated for each subject. Formula 2: [(Total minutes of static activity on weekdays $\times 5)+($ Total minutes of static activity on weekends $\times 2)$ ].

Formula $3(\mathrm{SQ}=\mathrm{SA} \div \mathrm{CA} \times 100$; Where $\mathrm{SQ}$ as Social Quotient, SA as Social Age and CA as Chronological Age) was used to calculate social quotient in VSMS. The result is the SQ score, on the basis of which the psychologist, based on the child's cognition and social norms, judges whether the score given by the child indicates a defect in adaptive behavior. Adaptive behavior means the adjustment of an individual according to his age regarding social, economic and cultural relations.
Then, TGMD-2 in both subscales was performed on all statistical samples. Because stability abilities develop at a much younger age, it was omitted. Each participant's execution of the gross motor skill items was videotaped (camera was at a 45-degree angle to the right) and later evaluated on the performance criteria by the principal investigator as well as an adapted physical education teacher who did not know the children. TGMD-2 scores were given based on the items listed in the test. Each skill was performed twice (score 1 when the child shows the desired criterion and score 0 for when the child does not show the desired criterion or shows it to be unstable). The skill score was given at the end by summing the standard scores.

\subsection{Statistical Analysis}

Statistical analyses were performed using SPSS (Version 19.0) for Windows (SPSS Inc., Chicago, IL, USA). The figures were created by GraphPad Prism v.9.0 (GraphPad Software, USA). Examination Kolmogorov-Smirnov (K-S) test used to reveal that all indices are distributed normally. Using Pearson correlation coefficient test, the relationship between research variables was investigated. Multiple linear regression analyses used to predict the outcome of a response variable. All statistical analyzes were performed at alpha level 0.05 .

\section{Results}

K-S test was used to determine the normality of data distribution. The results indicated that the research variables had normal distribution $(\mathrm{P}>0.05)$ and parametric method was applied. The characteristics of the participants Socio-demographic are shown in Table 1. Locomotor 
and Object-control skills scores for the children with LD are shown in Figure 2.

\begin{tabular}{|c|c|}
\hline Variables & Values \\
\hline No. & 82 \\
\hline \multicolumn{2}{|l|}{ Gender } \\
\hline Boy & $49(59.8)$ \\
\hline Girl & $33(40.2)$ \\
\hline Age, $y$ & $9.49 \pm 1.4$ \\
\hline Height, cm & $121.51 \pm 30.1$ \\
\hline Weight, kg & $34.15 \pm 10.7$ \\
\hline \multicolumn{2}{|l|}{ Grade } \\
\hline 1st grade & $6(7.3)$ \\
\hline 2nd grade & $35(42.7)$ \\
\hline 3rd grade & $23(28)$ \\
\hline 4th grade & $9(11)$ \\
\hline 5 th grade & $9(11)$ \\
\hline \multicolumn{2}{|l|}{ Residence (\%) } \\
\hline Urban & 84.6 \\
\hline Suburban & 9.8 \\
\hline Rural & 5.6 \\
\hline \multicolumn{2}{|l|}{ Type of house (\%) } \\
\hline Apartment & 72.9 \\
\hline House & 27.1 \\
\hline \multicolumn{2}{|l|}{ Gross motor skills, scores } \\
\hline Locomotor skills & $19.16 \pm 5.3$ \\
\hline Object-control skills & $19.33 \pm 5.4$ \\
\hline TGMD-2 & $38.75 \pm 10$ \\
\hline \multicolumn{2}{|l|}{ Daily activities, min } \\
\hline Organized activities & $13.32 \pm 21.1$ \\
\hline Static activities & $2620.3 \pm 955.8$ \\
\hline Social development, scores & $3.05 \pm 1.6$ \\
\hline
\end{tabular}

As seen in the Table 2, a Pearson test indicated that social development had a positive correlation with locomotor skills ( $\mathrm{r}=0.604, \mathrm{P}<0.001)$, object-control skills $(\mathrm{r}=$ $0.442, \mathrm{P}=0.003)$, TGMD-2 $(\mathrm{r}=0.53, \mathrm{P}=0.004)$, organized activities $(\mathrm{r}=0.69, \mathrm{P}<0.001)$, static activities $(\mathrm{r}=0.128$, $\mathrm{P}=0.412$ ). Organized activities had a positive correlation with locomotor skills ( $\mathrm{r}=0.478, \mathrm{P}<0.001)$, object-control skills $(\mathrm{r}=0.498, \mathrm{P}<0.001)$, TGMD-2 $(\mathrm{r}=0.411, \mathrm{P}<0.001)$. TGMD-2 had a positive correlation with locomotor skills ( $\mathrm{r}$ $=0.721, \mathrm{P}<0.001)$, object-control skills $(\mathrm{r}=0.854, \mathrm{P}=0.003)$.
Object-control skills had a positive correlation with locomotor skills ( $\mathrm{r}=0.351, \mathrm{P}=0.021)$.

Following the correlations, multiple linear regression analyses were used to identify the relative influence of the predictive variables (i.e. GMS and activities) on the social maturity in children with LD. A significant regression equation was found $(\mathrm{F}(2,79)=15.78, \mathrm{P}<0.001)$, with an $\mathrm{R}^{2}$ of 0.291 . Children with LD's predicted social maturity was equal to $0.648+0.322$ (activities) +0.084 (GMS) and GMS had the greatest effect on predicting the rate of social development in students with LD $($ Beta $=0.587)$. Social development was equal to $0.535+0.18$ (Locomotor skills) +0.411 (Object-control skills) and locomotor skills had the greatest effect on predicting the rate of social development in students with LD (Beta $=0.588)$. Social development was equal to $0.528+0.29$ (Organized activities).

\section{Discussion}

The main element of motor development is the FMS that are considered as gross motor and physical activities. Children with LD are at high risk for disabilities in the areas of learning, attention, and psychosocial action, and also have poor Social development.

In current study, organized activities and GMS (Locomotor and Object-control) in children with LD were positively associated with social development. Also, schoolaged children's GMS were positively related to their engagement in organized activities. Numerous studies have shown that motor skills are positively related to activities that are performed under the supervision of a trainer with special planning and mainly in groups $(1,12,13)$. Webster et al. (14) expressed that FMS have a complementary relationship with PA across childhood and adolescence. FMS are gross and fine motor patterns; gross motor patterns and PA are an important component of social role-playing (15). Evidence from some studies has shown that activities and the development of motor competence in children lead to grow emotionally, cognitively and physically (16).

Movement emerges from the interaction of 3 factors: the individual, the task, and the environment. The person creates movement to perform a motor task in a specific environment. That is why say that the individual, the task and the environment can effect on human behavior and even develop an active lifestyle. Following are the common constraints to motor learning experienced by a child with LD: learning disorder as specific LD, motor skills, physical status and finally social development $(5,17)$.

In other words, it can be said that the child's motor experiences at this time provide the basis for the child's subsequent knowledge and learning. That is, the development 
A

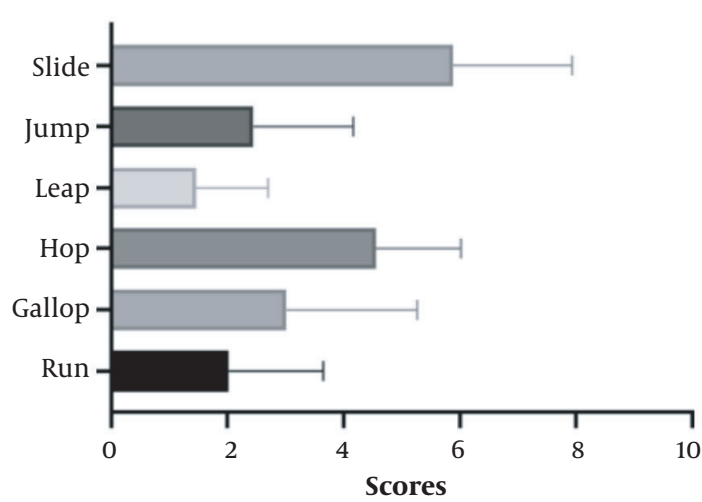

B object-Control Skills

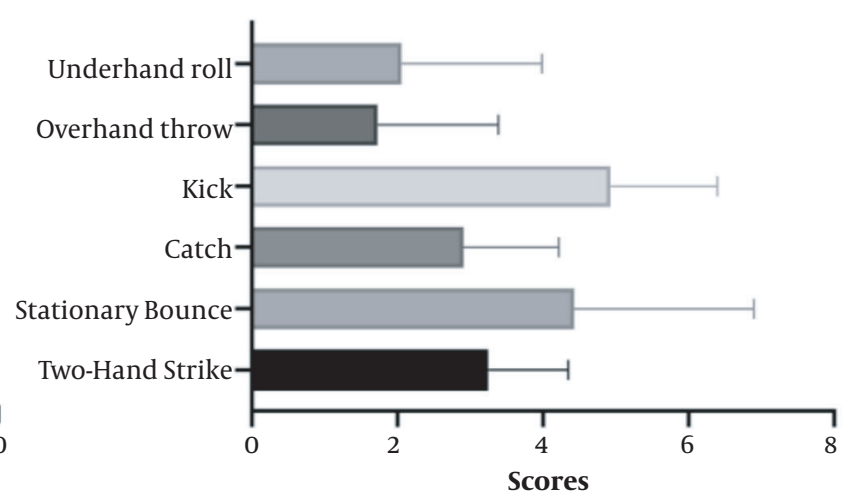

Figure 2. Gross motor skills scores for the children with LD; (A) Locomotor skills, (B) Object-control skills.

\begin{tabular}{|c|c|c|c|c|c|c|}
\hline & Locomotor Skills & Object-Control Skills & TGMD-2 & Organized Activities & Static Activities & Social Development \\
\hline Locomotor skills & 1 & $0.351^{*}$ & $0.721^{* *}$ & $0.478^{* *}$ & $0.215^{\mathrm{ns}}$ & $0.604^{* *}$ \\
\hline Object-control skills & & 1 & $0.854^{* *}$ & $0.498^{* *}$ & $0.189^{\mathrm{ns}}$ & $0.442^{* *}$ \\
\hline TGMD-2 & & & 1 & $0.411^{* *}$ & $0.178^{\mathrm{ns}}$ & $0.53^{* *}$ \\
\hline Organized activities & & & & 1 & $0.212^{\mathrm{ns}}$ & $0.69^{* *}$ \\
\hline Static activities & & & & & 1 & $0.128^{\mathrm{ns}}$ \\
\hline Social development & & & & & & 1 \\
\hline
\end{tabular}

${ }^{\mathrm{a}}{ }_{*} \mathrm{P}<.05 ;{ }^{* *} \mathrm{P}<.01 ; \mathrm{ns}=$ not significant.

of potential abilities and motor skills in sports and in general all daily activities require a minimum of motor skills, and even today's popular belief suggests that improving this factor, in addition to improving one's performance, reduces the risk of injury in all sports $(14,18)$. In fact, organized physical activity can enhance social skills such as responsibility, developing problem-solving skills, improving interpersonal relationships, decision-making, and social development in children with LD $(14,19)$. Because it makes children think, in addition to empathy, cooperation and ability in organized physical activities are strengthened and communication skills are developed. Due to PA and FMS, which lead to the improvement of the child's active behavior, the social context created also helps children to participate in PA and perform with FMS motivation, possibly affecting children's health behaviors (15).

Therefore, it can be concluded that in children with LD, with the improvement of GMS and organized activities, social development also increases and based on the results of the current study GMS (and its subcomponents: locomotor skills) had the greatest effect on predicting the rate of social development in students with LD. Explaining the results, it can be said that having a high level of these motor skills, especially GMS, increases the likelihood of participating in PA and can also simultaneously lead to the further development of children's social development $(14,15)$. Skills in locomotor skills enable the child to participate more in social activities and to increase their perceived competence and self-efficacy in activities and games $(5,15)$. Therefore, it can be concluded that the development of these skills reduces behavioral problems in children and has a positive effect on their behavioral status and social development.

This research also included some limitations: The heterogeneity of the subjects' families in terms of economic, social and cultural conditions, different personality traits and different age ranges of children can be one of the factors influencing this finding.

Future research should include longitudinal studies to examine the nature of the relationship between the development of GMS, PA, and social development with increasing age in children. 


\subsection{Conclusions}

The results of the present study show that children with higher levels of organized activities and motor skills performed better, and had higher social development, but high levels of static activities were not associated with social development. Because participation in physical education classes and programs plays an essential role in the development of children's FMS, and due to its impact on the social development of children with $\mathrm{LD}$, the organization of well-organized activities is of particular importance.

The results of this study, despite limitations, suggest that parents, coaches and teachers should pay more attention to the positive impact of organized physical activity and motor development on social development in children with LD and could provide preliminary support for other therapeutic interventions.

\section{Acknowledgments}

Thanks to all the parents who helped us collect the data.

\section{Footnotes}

Authors' Contribution: The study concept and design: DKH, SHSH and MM. Data acquisition: ME. Data analysis and interpretation: ME and MM. Drafting of the manuscript: ME and DKH. The critical revision of the manuscript for important intellectual content: DKH and SHSH. Statistical analysis: MM. Administrative, technical, and material support: DKH and SHSH. The study supervision: DKH and MM.

Conflict of Interests: There is no conflict of interest.

Ethical Approval: The study was carried out in accordance with Declaration of Helsinki 2018.

Funding/Support: This research received no external funding.

Informed Consent: Parents gave their written informed consent to the participation of their children in this research.

\section{References}

1. Westendorp M, Hartman E, Houwen S, Huijgen BC, Smith J, Visscher C. A longitudinal study on gross motor development in children with learning disorders. Res Dev Disabil. 2014;35(2):357-63. doi: 10.1016/j.ridd.2013.11.018. [PubMed: 24333806].

2. Mammarella IC, Ghisi M, Bomba M, Bottesi G, Caviola S, Broggi F, et al. Anxiety and Depression in Children With Nonverbal Learning Disabilities, Reading Disabilities, or Typical Development. J Learn Disabil. 2016;49(2):130-9. doi: 10.1177/0022219414529336. [PubMed: 24733818].
3. Zhang L, Zhu X, Haegele JA, Wang D, Wu X. Effects of a one-year physical activity intervention on fundamental movement skills of boys with severe intellectual disabilities. Res Dev Disabil. 2021;114:103980. doi: 10.1016/j.ridd.2021.103980. [PubMed: 33984668].

4. Zweers I, de Schoot RA, Tick NT, Depaoli S, Clifton JP, de Castro BO, et al. Social-emotional development of students with social-emotional and behavioral difficulties in inclusive regular and exclusive special education. Int J Behav Dev. 2020;45(1):59-68. doi: $10.1177 / 0165025420915527$.

5. Cavioni V, Grazzani I, Ornaghi V. Social and emotional learning for children with Learning Disability: Implications for inclusion. Int J emot. 2017;9(2):100-9.

6. Ulrich D. Examiner's Manual Test of Gross Motor Development (TGMD-2). Austin, TX, USA: PRO-ED; 2000.

7. Soltanian MA, Farokhi A, Ghorbani R, Moghaddam AJ, Zarezade M. [Evaluation of the reliability and construct validity of test of gross motor development-2 (Ulrich 2) in children of Semnan province]. Koomesh. 2013;14(2):200-6. Persian.

8. Aaron DJ, Kriska AM, Dearwater SR, Cauley JA, Metz KF, LaPorte RE. Reproducibility and validity of an epidemiologic questionnaire to assess past year physical activity in adolescents. Am J Epidemiol. 1995;142(2):191-201. doi: 10.1093/oxfordjournals.aje.a117618. [PubMed: 7598119].

9. Vazini Taher A, Hayati A, Pakzamir F. [Relationship of Level of Physical Activities and Fundamental Movement Skills among Elementary School's Children]. Mot Behav. 2014;5(14):163-78. Persian.

10. Sendhilkumar R. The Prevalence of Problem Behaviours among Children with Mild and Moderate Intellectual Disability. Int J Res Appl Sci Eng Tech. 2020;8(6):1449-51. doi: 10.22214/ijraset.2020.6236.

11. Tajar J. [Psychological Analyzing of Unsupervised Children in Iran]. Adv Environ Biol. 2014;8(13):885-93. Persian.

12. Abdelkarim $\mathrm{O}$, Ammar $\mathrm{A}$, Trabelsi $\mathrm{K}$, Cthourou $\mathrm{H}$, Jekauc $\mathrm{D}$, Irandoust $\mathrm{K}$, et al. Prevalence of Underweight and Overweight and Its Association with Physical Fitness in Egyptian Schoolchildren. Int J Environ Res Public Health. 2019;17(1). doi: 10.3390/ijerph17010075. [PubMed: 31861878]. [PubMed Central: PMC6981920].

13. Westendorp M, Hartman E, Houwen S, Smith J, Visscher C. The relationship between gross motor skills and academic achievement in children with learning disabilities. Res Dev Disabil. 2011;32(6):2773-9. doi: 10.1016/j.ridd.2011.05.032. [PubMed: 21700421].

14. Webster EK, Martin CK, Staiano AE. Fundamental motor skills, screen-time, and physical activity in preschoolers.J Sport Health Sci. 2019;8(2):114-21. doi: 10.1016/j.jshs.2018.11.006. [PubMed: 30997257]. [PubMed Central: PMC6450921].

15. Eslami Nosratabadi M, Sangari M, Mirmoezzi M. [The Effect of Cognitive Rehabilitation, Physical and Concurrent Training on Sustained, Selective and Shifting Attention in Children with ADHD]. Iran J Psychiatry Behav Sci. 2021;27(3):1-10. Persian. doi: 10.32598/ijpcp.27.3.3342.1.

16. Martinez-Bello VE, Estevan I. Physical Activity and Motor Competence in Preschool Children. Children (Basel). 2021;8(4). doi: 10.3390/children8040305. [PubMed: 33923383]. [PubMed Central: PMC8071540].

17. Nerurkar A, Singh S. To Study the Effects of Play Therapy on Motor Function and Social Maturity in Children with Cerebral Palsy. Int JTher Rehabil Res. 2016;5(5):227. doi: 10.5455/ijtrr.000000211.

18. Seghatoleslamy A, Masoudi M, Saghebjoo M, Taheri M. Aerobics or Pilates: Which is More Effective in the Performance of Wechsler Acid Profile Among Children with Learning Disabilities? A Randomized Comparison Trial. Int J Sch Health. 2019;6(3). doi: 10.5812/intjsh.90020.

19. Hattabi S, Bouallegue M, Mhenni T, Halouani J, Chtourou H. Effect of a Plyometric Training Program on the Physical Parameters of ADHD Children: Behavioral and Cognitive Consequences. Int J Sport Stud Hlth. 2021;4(1). e118756. doi: 10.5812/intjssh.118756. 